\title{
Comparison of CSES ionospheric RO data with COSMIC measurements
}

\author{
Xiuying Wang ${ }^{1}$, Wanli Cheng ${ }^{2}$, Zihan $\mathrm{Zhou}^{1}$, Song $\mathrm{Xu}^{1}$, Dehe Yang ${ }^{1}$, and Jing Cui ${ }^{1}$ \\ ${ }^{1}$ Institute of Crustal Dynamics, China Earthquake Administration, Beijing, China \\ ${ }^{2}$ Xinyang Station, Henan Earthquake Administration, Henan, China \\ Correspondence: Xiuying Wang (652383915@qq.com)
}

Received: 27 May 2019 - Discussion started: 19 June 2019

Revised: 11 October 2019 - Accepted: 14 October 2019 - Published: 13 November 2019

\begin{abstract}
CSES (China Seismo-Electromagnetic Satellite) is a newly launched electric-magnetic satellite in China. A GNSS occultation receiver (GOR) is installed on the satellite to retrieve electron density related parameters. In order to validate the radio occultation (RO) data from the GOR on board CSES, a comparison between CSES RO and the colocated COSMIC RO data is conducted to check the consistency and reliability of the CSES RO data using measurements from 12 February 2018 to 31 March 2019. CSES RO peak values ( $N m \mathrm{~F} 2)$, peak heights $(\mathrm{hmF} 2)$, and electron density profiles (EPDs) are compared with corresponding COSMIC measurements in this study. The results show that (1) $N m \mathrm{~F} 2$ between CSES and COSMIC is in extremely good agreement, with a correlation coefficient of 0.9898 . The nearzero bias between the two sets is $0.005363 \times 10^{5} \mathrm{~cm}^{-3}$ with a RMSE of $0.3638 \times 10^{5} \mathrm{~cm}^{-3}$, and the relative bias is $1.97 \%$ with a relative RMSE of $16.17 \%$, which are in accordance with previous studies according to error propagation rules. (2) $h m \mathrm{~F} 2$ between the two missions is also in very good agreement with a correlation coefficient of 0.9385 ; the mean difference between the two sets is $0.59 \mathrm{~km}$ with a RMSE of $12.28 \mathrm{~km}$, which is within the error limits of previous studies. (3) Co-located EDPs between the two sets are generally in good agreement, but with a better agreement for data above $200 \mathrm{~km}$ than those below this altitude. Data at the peak height ranges show the best agreement, and then data above the peak regions; data below the peak regions, especially at the altitude of about the E layer, show relatively large fluctuations. It is concluded that CSES RO data are in good agreement with COSMIC measurements, and the CSES RO data are applicable for most ionosphere-related studies considering the wide acceptance and application of COSMIC RO measure-
\end{abstract}

ments. However, particular attention should be paid to EDP data below peak regions in application as data at the bottom side of the profiles are less reliable than that at the peak and topside regions.

\section{Introduction}

The first China Seismo-Electromagnetic Satellite (CSES), also called ZH-1 in China, has been working for over 1 year since its launch on 2 February 2018. This satellite is the first spaced-based geophysical field measurement platform in China, which can be used for the 3-D earthquake observation when combining with the ground-based observation system; a subsequent satellite of this series will be launched in 2022 and the engineering work is under way. The primary scientific objectives of the CSES mission are to obtain worldwide data on the space environment of the electromagnetic field, ionospheric plasma, and charged particles; to monitor and study the ionospheric perturbations which may possibly associated with earthquake activity, especially with those destructive ones; to support the research on geophysics, space sciences, electric wave sciences, and so on; and also to provide the data sharing service for international cooperation and scientific community (Shen et al., 2018).

The CSES satellite is in a sun-synchronous orbit with an inclination angle of $97.4^{\circ}$ at the altitude of $507 \mathrm{~km}$. The times of descending and ascending nodes are 14:00 and 02:00 LT (local time) respectively. It takes about $94.6 \mathrm{~min}$ to complete a circular orbit, thus about 15 orbits per day. The revisiting period of CSES is $5 \mathrm{~d}$, which means the satellite will nearly repeat the orbits after $5 \mathrm{~d}$. At present, the observation range 
of the CSES satellite is mainly between -65 and $+65^{\circ}$ of geographic latitudes (Wang et al., 2019).

There are eight Chinese payloads and one Italian payload on board the CSES satellite, belonging to three categories: (1) electromagnetic observations, including a searchcoil magnetometer (SCM), electric field detector (EFD), and high precision magnetometer (HPM); (2) ionosphere related observations, including those measured using a GNSS occultation receiver (GOR), plasma analyzer package (PAP), Langmuir probe (LAP), and tri-band beacon (TBB); (3) and high-energy particle observations, including the high energetic particle package (HEPP) and high energetic particle package detector (HEPD), of which HEPD is provided by the Italian Space Agency.

Of the eight payloads, four are related to ionospheric parameter observations. The GOR payload on board CSES is a GPS/BD2 receiver to retrieve ionospheric electron densities according to the radio wave refractivity when traversing the ionosphere. It is known that GPS/GNSS radio occultation (RO) based on a low Earth orbit (LEO) has been a powerful technique in ionosphere monitoring; using this technique, the accurate electron density profiles (EDPs) in the ionosphere can be derived with high vertical resolution on a global scale from bending information of the RO signals (Kuo et al., 2004; Rocken et al., 2000; Schreiner et al., 1999). Therefore, many LEO satellites were launched with the RO payload after the pioneer RO experiment on the GPS/MET mission (Hajj and Romans, 1998; Schreiner et al., 1999), such as the CHAMP satellite (Jakowski et al., 2002; Wickert et al., 2009), the GRACE satellites (Beyerle, 2005), the most famous COSMIC mission (Anthes et al., 2008; Lei et al., 2007), and so on. The application of the RO technique is also an important part of the CSES satellite. Combined with the in situ electron density measurements on board CSES, the CSES RO-retrieved electron densities can be used to study global-scale ionospheric 3-D images from the bottom of the ionosphere to the altitude of the CSES satellite using the large amount of daily occultation events. However, a complete and thorough validation of the RO measurements obtained by the CSES satellite is a necessary work before the retrieved electron density profiles can be used for ionospheric studies.

A primary comparison, between CSES and COSMIC using the global distribution of peak values $(N m \mathrm{~F} 2)$ and peak heights $(h m \mathrm{~F} 2)$ data, was carried out during the in-orbiting test period of the CSES satellite, and the CSES NmF2 values were also compared with the measurements from three digisondes in China (Cheng et al., 2018). According to this paper, both the comparisons show that the CSES RO $N m$ F2 data are generally consistent with measurements from COSMIC and ionosondes. However, quantitative errors and application suggestions are not given in this paper. Moreover, the comparisons are limited to the peak values and the data only covers 2 months. Therefore, a more complete validation is still required to assess the consistency and reliability of the
RO profiles obtained by the CSES satellite. A large amount of RO profiles have been obtained so far by CSES, which provide enough data to implement a more detailed validation work.

Validation of RO profiles is usually done by comparing the profiles with the measurements from ionospheric vertical sounding or incoherent scatter radars (ISRs). However, $\mathrm{RO}$ electron density profiles above the F2 peak region cannot be validated by ionosonde observations due to the unreliable extrapolating data at these altitudes. In addition, the uneven distribution of the ionosonde stations, most located on continental areas and fewer in the ocean areas, restricts the global comparison work. Although ISRs can be used to validate RO electron density profiles above $\mathrm{F} 2$ peak region, this comparison is limited due to the relatively small number of ISR sites as well as their limited operating time. Therefore, we will carry out the comparison work using the RO measurements from the COSMIC dataset in this paper.

Validation of the COSMIC electron density measurements has been performed in numerous studies using different measurements, such as the cross-validation of the retrieved profiles from nearby spacecraft in the same COSMIC mission (Schreiner et al., 2007), comparison with ground-based ionosondes and ISRs (Cherniak and Zakharenkova, 2014; Chu et al., 2010; Chuo et al., 2011; Habarulema et al., 2014; Kelley et al., 2009; Krankowski et al., 2011; Lei et al., 2007; McNamara and Thompson, 2015), comparison with the in situ electron density measurements (Lai et al., 2013; Pedatella et al., 2015; Yue et al., 2011), comparison with radio tomography data using a space climatology phenomenon (Thampi et al., 2011), comparison with the ionospheric model International Reference Ionosphere (IRI; Lei et al., 2007; Wu et al., 2015; Yang et al., 2009), and so on. As COSMIC RO data have been extensively validated and widely accepted for application, COSMIC RO data are used to validate the in situ plasma density observations from the Swarm constellation (Lomidze et al., 2018). We therefore also try to use the COSMIC RO dataset to validate CSES RO measurements because of its relative large amount of data with global spatial coverage. In addition, similar ROretrieved data from the two sets also provide a unique opportunity to check the consistency and reliability of CSES NmF2 and $h m \mathrm{~F} 2$ parameters as well as RO profiles.

In this study, the validation work is implemented by comparing CSES $N m \mathrm{~F} 2, h m \mathrm{~F} 2$, and data from EDPs at some selected altitudes with corresponding COSMIC measurements, and the bias and RMSE between the two sets are then calculated and estimated to evaluate the consistency and reliability of CSES RO-retrieved data. Based on the results, an application suggestion is given on the CSES ionospheric RO data. 


\section{Data and method}

\subsection{CSES and COSMIC RO data}

\subsubsection{CSES RO data}

The GOR payload on board CSES can receive the dual frequencies from GPS (L1: $1575.42 \pm 10 \mathrm{MHz}$; L2: $1227.6 \pm$ $10 \mathrm{MHz}$ ) and DB2 (L1: $1561.98 \pm 2 \mathrm{MHz}$; L2: $1207.14 \pm$ $2 \mathrm{MHz}$ ) to retrieve atmospheric and ionospheric parameters with sampling rate of 100 and $20 \mathrm{~Hz}$ respectively. Firstly, TECs from GPS to LEO are calculated from the carrier phase of the dual frequencies; and then electron densities are retrieved from TECs using the Abel integration transformation. The Abel integration method and assumptions used in the RO inversion process have been described in detail in many publications (Kuo et al., 2004; Lei et al., 2007; Schreiner et al., 1999) and will therefore not repeat here.

The GOR payload on board CSES started to work on 12 February 2018 and ionospheric RO measurements have been conducted since then. CSES RO-retrieved data are divided into five levels: $0,1,2,2 \mathrm{~A}$, and 3 . Level-0 is original data; Level-1 is physical quantity in time order; Level2 is physical quantity data with satellite orbital information and geomagnetic coordinates, while Level-2A is similar to Level 2, but with higher precise orbital information; and Level-3 is a 2-D structural data product from Level-2 and Level-2A, which can provide peak value, peak height, and EDP data.

All the CSES RO data of the five levels are saved in HDF5 format, which is organized in a hierarchical way. One file is saved for each occultation event, and about 500 to $600 \mathrm{oc}-$ cultation event files can be obtained per day. Data users can refer to the data specification document for detailed description of data file naming conventions and data level classification, which can be obtained from the CSES data sharing center website: http://www.leos.ac.cn (last access: 27 September 2019).

More than 180000 CSES occultation profiles have been obtained from 12 February 2018 to 31 March 2019, of which occultation events co-located with that from the COSMIC mission are used to carry out the comparison and validation work in this paper.

\subsubsection{COSMIC RO data}

The COSMIC (Constellation Observing System for Meteorology, Ionosphere, and Climate, also called FORMOSAT-3 in Taiwan) mission, a constellation of six identical low Earth orbit satellites launched in April 2006, is a joint TaiwanUS mission to observe the near-real-time GPS RO data (Anthes et al., 2008). COSMIC RO data come from the GPS Occultation Experiment (GOX) receivers on board the COSMIC satellites that monitor the two GPS L-band signals to establish the relative geometries of satellite positions

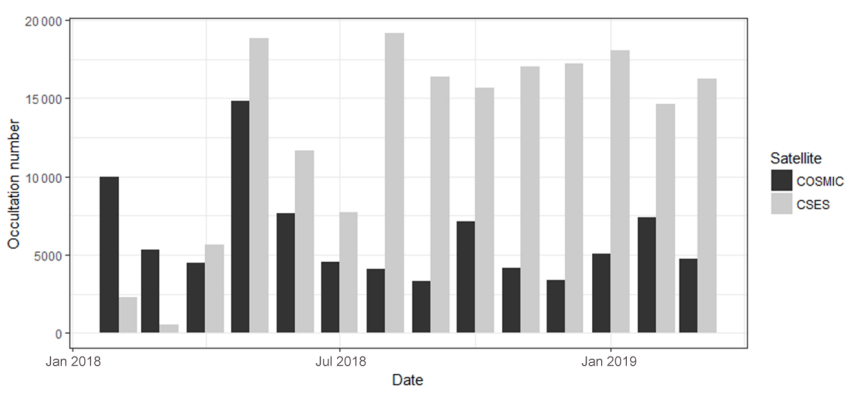

Figure 1. Occultation number per month from February 2018 to March 2019 for both CSES and COSMIC.

and differences in phase and Doppler shifts (Rocken et al., 2000). At the University Corporation for Atmospheric Research (UCAR) COSMIC Data Analysis and Archive Center (CDAAC), ionospheric profiles are retrieved using of the Abel inversion technique from TEC along LEO-GPS rays. Detailed descriptions of CDAAC data processing and EDP retrieval method can be found in some literature (Kuo et al., 2004; Lei et al., 2007).

In the present study, the COSMIC level-2 electron density profiles provided as "ionPrf" files from 12 February 2018 to 31 March 2019 are used, which can be downloaded from the CDAAC website: https://cdaac-www.cosmic.ucar.edu/ (last access: 9 November 2011). COSMIC can provide over 2000 $2500 \mathrm{RO}$ profiles per day at its initial stage, but for now only 200-300 events on average can be obtained each day. Figure 1 gives the total occultation numbers of each month for both CSES and COSMIC missions from February 2018 to March 2019.

From Fig. 1 it can be seen that over 15000 occultation events can be obtained by CSES each month, or over 500 per day on average, after the initial in-orbit testing stage from February to July 2018. In contrast, occultation numbers from COSMIC are much lower; there are only about 200 occultations on average each day. A total of over 86000 occultation events have been obtained from the COSMIC data center from February 2018 to March 2019.

Based on these two datasets from CSES and COSMIC, the co-located occultations within defined spatial and temporal criteria from the two measurements are selected and used to carry out the comparison work.

\subsection{Data selection}

In order to make the comparison between CSES and COSMIC RO data as accurate as possible, spatial and temporal criteria must be defined to select matching occultation profiles for subsequent comparison analysis.

Before determining the selection criteria, it should be pointed out here that RO-retrieved electron density profiles are different from those obtained by vertical ISR observations. For the latter, the observation point is fixed, and all the 
data points of different altitudes on the profiles correspond to this fixed observation point; but for the former, both the LEO and GPS are in motion during the occultation process, and therefore data points of different altitudes on the profile correspond to different point on the ground. The geographic location of the tangent points of a RO-retrieved profile may vary by several hundred kilometers, which means the spatial range of a profile can cover several degrees in horizontal latitudinal and longitudinal range, and several hundred kilometers in vertical altitude range. However, the ionospheric spatial correlation can extend to a large area, as suggested by some research (Shim et al., 2008; Yue et al., 2007). According to Shim et al. (2008), the daytime meridional correlation lengths are approximately 9 and $5^{\circ}$ at middle and low latitudes, and the nighttime values are about 3 and $2^{\circ}$ at middle and low latitudes, respectively; the zonal correlation lengths are $23^{\circ}$ at midlatitudes and $15^{\circ}$ at low latitudes during the day, and are $11^{\circ}$ at midlatitudes and $10^{\circ}$ at low latitudes during the night. Therefore, the matching profile pairs from the two missions must be within the correlation distances. Considering the relatively small number of occultation events from the COSMIC measurements, we define the search criteria for co-located occultation events as follows: (1) the time difference between the matching occultation pairs is less than $30 \mathrm{~min}$; (2) the distance differences between the locations of the two occultation events are within $2^{\circ} \times 6^{\circ}$ range in latitudinal and longitudinal directions. Here, the tangent point at the F2 peak value of an occultation profile is defined as the location of the occultation event. The reason to use the peak value tangent point as the occultation location is because the peak value is normally located at the middle of a profile for the CSES EDPs, and in this way the spatial differences of the corresponding points, especially the top and bottom points, between the matching profile pairs can be limited to the correlation distance range as much as possible.

Based on the above criteria, the RO profiles from CSES and COSMIC, covering the period from February 2018 to March 2019, are searched to select the co-located profile pairs. The profiles with $N m \mathrm{~F} 2$ appearing below 200 or above $500 \mathrm{~km}$ are discarded, and profiles with only an ascending or descending part of a profile which cannot determine the peak values are also deleted from the CSES dataset. A total of 845 matched profiles are found, and their distributions are given in Fig. 2. Numbers of occultation in each 10 latitudinal region are also calculated and given in Fig. 3.

From Fig. 2, it can be seen that the selected profile pairs are globally distributed, which makes the data representative of the whole dataset on a spatial scale. In addition, the time coverage of the co-located occultation pairs is over a year, including different periodic components of the ionospheric variations, which also makes the data involved in the comparison representative on a temporal scale.

It is necessary to note that because the CSES satellite is in a sun-synchronous orbit as mentioned earlier, the local time of the occultation events is concentrated around the ascend- ing (02:00) and descending (14:00) local time, while COSMIC data cover all the local time. Therefore, special attention should be paid to the local-time issue when combing CSES and COSMIC RO data together for data analysis; that is, occultation events with similar local time as that of CSES must be selected from the COSMIC dataset. This local time issue is not considered by Cheng et al. (2018) when they compared CSES RO data with that from COSMIC; therefore their result is questionable.

Another point to note is that most of the selected profile pairs are distributed in the midlatitude regions, as shown in Figs. 2 and 3, and the equatorial region as well as the highlatitude regions exhibit a lower number of occultation events, which ensures that the selection criteria can be satisfied for most of the selected matched profiles.

\subsection{Comparison method}

The CSES RO electron density data are compared with the co-located COSMIC RO data to assess the consistency and reliability of the CSES RO data relative to the COSMIC data, and then the consistency and reliability of the CSES RO data relative to ground-based measurements are estimated using the results obtained by previous research on COSMIC RO data according to error propagation rules.

The maximum electron density and its height, namely $N m \mathrm{~F} 2$ and $h m \mathrm{~F} 2$ from CSES RO data, are compared and analyzed directly with the corresponding co-located COSMIC data, respectively. Besides RO peak values, the profiles of the matched pairs are also compared in this study. To compare the similarities of the profiles, average electron density data near some special altitudes of a profile are calculated and compared. Because the orbit altitude of CSES is $507 \mathrm{~km}$, only data below this altitude are obtained from the CSES ROretrieved EDPs. Therefore, some altitudes below this altitude are selected, including 100,150, 200, 250, 300, 350, 400, 450 , and $500 \mathrm{~km}$. It should be pointed out here that selection of these altitudes is made for the simplification and ease of calculation. The consistency and reliability of the CSES RO profiles are thus evaluated by combining the comparison results of these selected altitudes.

Normally, the height resolution in the F region is of the order of $20 \mathrm{~km}$ for the COSMIC RO (Kuo et al., 2004), but CSES RO data have a higher resolution due to the higher sampling rate of the radio signals. We therefore use the average data between the selected altitudes $\pm 10 \mathrm{~km}$, which are just within the vertical resolution of the COSMIC RO data.

In this study, all the selected matched profiles are involved in the analysis rather than those observed in geomagnetically quiet days. In this way, disturbed data caused by events such as geomagnetic storms can also be used to compare their similarities or differences under these special occasions. 


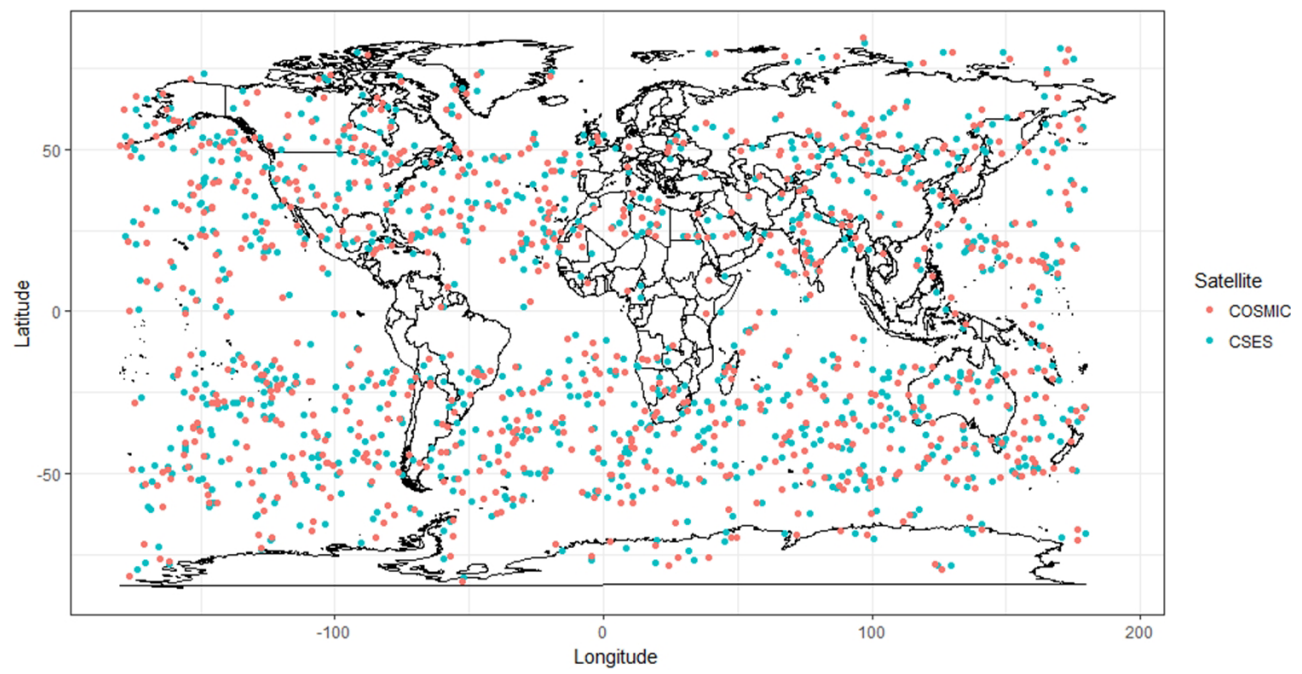

Figure 2. Distribution of the selected profile pairs. (Each dot indicates the location of the tangent point of the maximum values in a profile.)

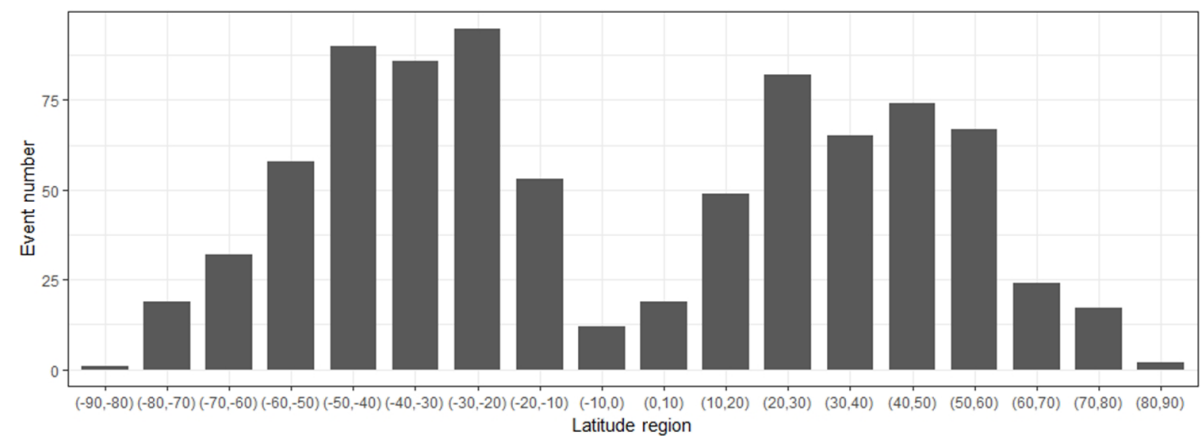

Figure 3. Number of co-located profile pairs along latitudinal regions.

\section{Results and discussions}

\subsection{Comparison of $\mathrm{NmF2}$}

The maximum electron density in the ionospheric F2 layer, $N m \mathrm{~F} 2$, is the most important parameter in ionosphere-related studies. To compare this parameter, the maximum electron density data are extracted from all the matched RO files of CSES and COSMIC measurements. A scatter plot of these matched $N m \mathrm{~F} 2$ points is given in Fig. 4; also given is the histogram of the data differences between the matched peak value points. As shown in Fig. 4b, data differences between the two measurements are normally distributed; points with data differences exceeding 3 times the RMSE, shown as open circles in Fig. 4a, are considered outliers and can be eliminated from the selected dataset according to the $3 \sigma$ rule. Red points in Fig. 4a are peak values observed during geomagnetic storm conditions of Dst $<-30 \mathrm{nT}$ and all are within $3 \sigma$ limits and matched very well, as shown in Fig. 4a. Figure 4a also gives the linear fitting equation, the goodness-of-fit coefficient $R^{2}$ (square of correlation coefficient), and the number of data points after the elimination of outliers.
The correlation coefficient between the two matched $N m \mathrm{~F} 2$ sets after the elimination of outliers is 0.9898 , and the correlation coefficient before the elimination of outliers is 0.9795 , both of which can pass the significance test of a 0.01 confidence level. The high correlation coefficient indicates the high consistency between the two $N m \mathrm{~F} 2$ sets. The linear fitting coefficient of 0.9834 given in Fig. 4 a is very close to 1 ; the data differences between the two sets are nearly normally distributed, as shown in Fig. 4b, and most of the data differences is around zero, all of which mean that the CSES NmF2s are almost equal to COSMIC $N m \mathrm{~F} 2 \mathrm{~s}$ with a nearly-zero bias. Both the correlation coefficient and the linear fitting coefficient indicate that the CSES $N m$ F2s are in extremely good agreement with the corresponding COSMIC data.

To quantify the error, we also calculate the RMSE and relative RMSE between the two sets. The mean of the data differences between CSES $N m \mathrm{~F} 2$ and COSMIC $N m \mathrm{~F} 2$ is $0.005363 \times 10^{5} \mathrm{~cm}^{-3}$, and the RMSE between the two matched datasets is $0.3638 \times 10^{5} \mathrm{~cm}^{-3}$, both of which are very low when compared with the original data. Therefore, the nearly-zero bias between the two measurements of $\mathrm{NmF} 2$ 

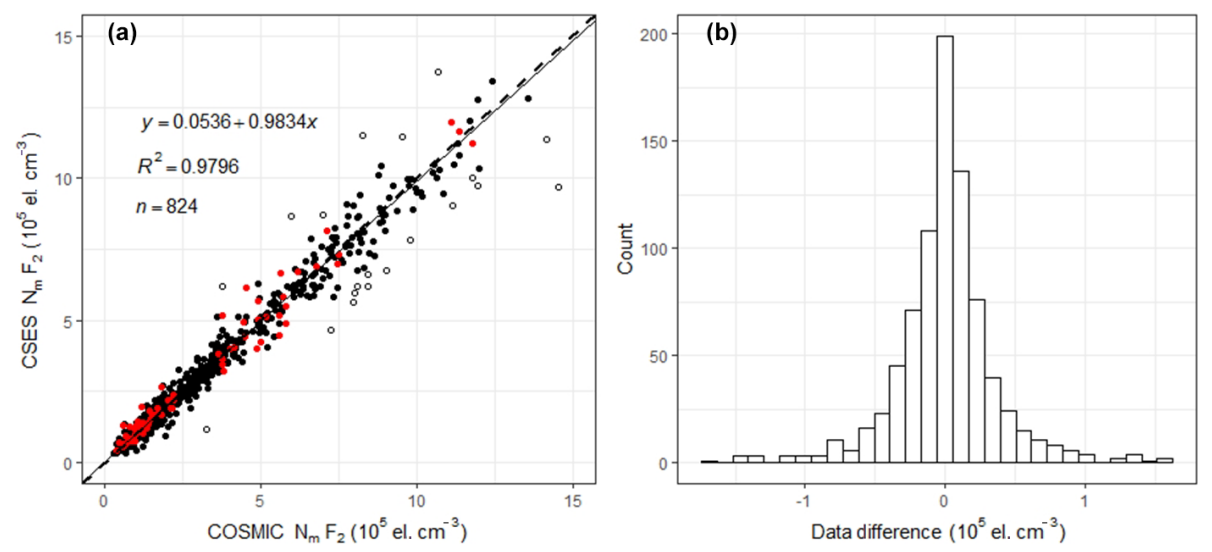

Figure 4. Scatter plot of matched $N m F 2 s$ and histogram of the data differences between the two sets. The dashed line in (a) is the equal value line with a slope of 1 , and the solid line is the linear fitting line. Open circles are points exceeding 3 times the RMSE. Red solid points are data observed when Dst $<-30 \mathrm{nT}$. $y$ refers to CSES $N m \mathrm{~F} 2$ data, $x$ COSMIC $N m \mathrm{~F} 2$ data. $R^{2}$ is the goodness-of-fit coefficient; $n$ is the total data number after eliminating outliers.

can be neglected, which is in accordance with the normal distribution, with most data differences clustering around zero, as shown in Fig. 4b. The mean relative differences or mean relative deviation (MRD) of $N m \mathrm{~F} 2$ is $1.97 \%$, and the corresponding relative RMSE is $16.17 \%$. The MRD is also extremely low. The mean of data differences and the mean of relative data differences, as well as their RMSEs, again show that the CSES RO data are in very good agreement with the COSMIC data.

To compare the difference in the correlation relationship for daytime and nighttime data, the data in Fig. 4 are divided into two groups. As introduced in Sect. 2.2, the time of the CSES satellite is fixed at 02:00 LT during the night and 14:00 LT during the day, and the local times of RO data are around these two fixed local times; we therefore do not need to further consider differences caused by different local times.

The scatter plots for daytime and nighttime data are drawn using the same method introduced above and given in Fig. 5. The data obtained under geomagnetic storm conditions are also shown in red color, all of which are within the $3 \sigma$ limits.

The correlation coefficient for daytime data after the elimination of outliers is 0.9759 , and 0.9628 before the elimination of outliers; for nighttime data after the elimination of outliers, the correlation coefficient is 0.9249 , and 0.8916 for all the data. The higher daytime correlation coefficient indicates a better agreement for the daytime data than the nighttime data. This can be seen clearly from Fig. 5; the nighttime data obviously fluctuate more violently.

The mean data difference for daytime data is $-0.04346 \times$ $10^{5} \mathrm{~cm}^{-3}$, with a RMSE of $0.5865 \times 10^{5} \mathrm{~cm}^{-3}$, and the mean data difference for nighttime data is $0.01215 \times 10^{5} \mathrm{~cm}^{-3}$, with a RMSE of $0.1998 \times 10^{5} \mathrm{~cm}^{-3}$. The opposite sign of the daytime and nighttime mean data differences indicates that the CSES daytime data are slightly lower than that of the COSMIC, while CSES nighttime data are slightly higher than the corresponding COSMIC data, but both the means of data differences are extremely low and can be considered to have zero bias when compared with the original measurements.

When comparing the different results given in Table 1, the absolute mean data differences for daytime data are obviously greater than those of the overall result, and with a larger RMSE, and the mean data differences for nighttime data are also greater than the overall result, but with a lower RMSE. It seems that nighttime data are in better agreement than daytime data. However, the two plots in Fig. 5 indicate that the daytime data is obviously better than the nighttime data. This is because the daytime data are much higher than nighttime data, absolute error cannot correctly reflect the real situation when comparing data values with different magnitudes. We therefore calculate the relative errors for both the daytime and nighttime data. The mean relative data difference for daytime data is $0.79 \%$ with a relative RMSE of $12.76 \%$, and the mean relative data difference for nighttime data is $2.61 \%$ with a relative RMSE of $18.14 \%$, which indicates an obviously better agreement for the daytime measurements.

It is necessary to point out that most of the daytime data points with higher values are located below the dashed lines as shown in Fig. 5, which means that the COSMIC $N m F 2 s$ are larger than those of the CSES, so there is a negative bias between the two sets, while for nighttime data, most of the data points with higher values are above the dashed line, indicating higher CSES $N m \mathrm{~F} 2$ values, thus there is a positive bias between them. This can also explain why there is a higher correlation coefficient and a smaller mean data difference when combining daytime and nighttime data together.

Another issue should be pointed out here. As can be seen from Table 1, the absolute mean difference for daytime data is negative, while the mean relative difference is positive. 

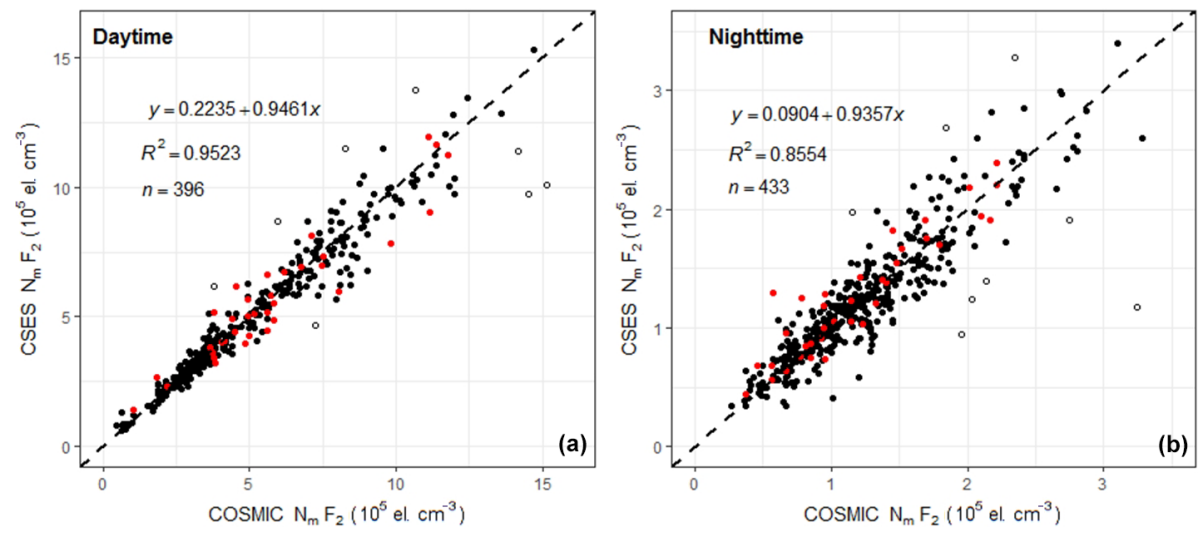

Figure 5. Scatter plot of $N m \mathrm{~F} 2$ for daytime and nighttime data. (The dashed line in $\mathbf{a}$ and $\mathbf{b}$ is the equal value line with a slope of 1.)

Table 1. Absolute and relative error of $N m \mathrm{~F} 2$ between CSES and COSMIC.

\begin{tabular}{llrr|rr}
\hline & Correlation & \multicolumn{2}{c|}{ Absolute error } & \multicolumn{2}{c}{ Relative error } \\
\cline { 3 - 6 } & coefficient & Mean $\left(\mathrm{cm}^{-3}\right)$ & RMSE $\left(\mathrm{cm}^{-3}\right)$ & Mean & RMSE \\
\cline { 3 - 6 } & & $0.005363 \times 10^{5}$ & $0.3638 \times 10^{5}$ & $1.97 \%$ & $16.17 \%$ \\
Total & 0.9898 & $-0.04346 \times 10^{5}$ & $0.5865 \times 10^{5}$ & $0.79 \%$ & $12.76 \%$ \\
Daytime & 0.9759 & $0.01215 \times 10^{5}$ & $0.1998 \times 10^{5}$ & $2.61 \%$ & $18.14 \%$ \\
\hline
\end{tabular}

Results of all the coefficients and absolute errors maintain four significant digits, and relative errors maintain two digits after decimal point. Zeros are padded after the decimal point for some results to maintain an identical power exponent.

Further analysis shows that these different signs are caused by some points with much higher CSES $N m \mathrm{~F} 2$ values.

Here, we compare our results with previous studies and do some analysis.

Lei et al. (2007) obtained a correlation coefficient of 0.85 when comparing COSMIC NmF2 with observations from 31 globally distributed SPIDR (The Space Physics Interactive Data Resource) ionosondes using data observed in July 2006. Chuo et al. (2013) demonstrated that COSMIC-derived $N m \mathrm{~F} 2$ values are in good agreement with digisonde observations of different seasons; they also reported an agreement about 0.96 using observations from a lower latitude ionosonde in the Southern Hemisphere using a big dataset from May 2006 to April 2008. Chu et al. (2010) found a correlation coefficient of 0.98 when comparing $N m \mathrm{~F} 2 \mathrm{~s}$ between COSMIC and 60 globally distributed ionosondes belonging to SWPC (Space Weather Prediction Center), NOAA, using data from November 2006 to February 2007. Krankowski et al. (2011) obtained a very good correlation coefficient of 0.986 when validating COSMIC RO data in 2008 using measurements from European midlatitude ionosondes. Our result of 0.9898 is quite similar to or even slightly better than those results, when considering the similar solar activity levels. A relatively high correlation coefficient between CSES $N m \mathrm{~F} 2$ and ionosondes can be deduced since the correlation transitive conditions are satisfied according to Langford et al. (2001). We therefore obtained that CSES RO de- rived peak values are in very good agreement with COSMIC and ground-based measurements.

For $N m$ F2 relative errors, Krankowski et al. (2011) obtained a mean relative bias of $0.72 \%$ with a standard deviation of $8.42 \%$, and the slope of the linear fitting line is 0.994 using a manual selected dataset in Europe, which is better than the results in this paper. Wu et al. (2009) got a $-3.2 \%$ relative bias with a standard deviation of $20.7 \%$ when comparing $N m \mathrm{~F} 2 \mathrm{~s}$ between COSMIC and 62 global ionosondes from SPIDR using data from July 2006 to December 2007. Yue et al. $(2011,2013)$ suggest that the ability to retrieve $N m \mathrm{~F} 2$ using the Abel inversion technique has an uncertainty of about $10 \%$. Based on the linear fitting equation between CSES and COSMIC and on the $N m \mathrm{~F} 2$ relative errors between COSMIC and ground-based measurements, we can deduce that the relative errors between CSES peak values and ground-based measurements are comparable to prior results according to error propagation rules.

As to the absolute error, Kelley et al. (2009) obtained a RMSE of $1.0 \times 10^{5} \mathrm{~cm}^{-3}$ when comparing COSMIC data with ISR; Hajj and Romans (1998) obtained a NmF2 RMS difference of about $1.5 \times 10^{5} \mathrm{~cm}^{-3}$ when comparing the GPS/MET measurements with nearby ionosonde data, and Jakowski et al. (2002) also obtained a similar RMS difference of about $0.9 \times 10^{5} \mathrm{~cm}^{-3}$ when comparing the CHAMP RO measurements to the in situ Langmuir probe data on the same satellite. Habarulema et al. (2014) suggested that all 
RO datasets are close to the ionosonde data within a similar error margin for both midlatitude and low-latitude regions when comparing COSMIC, GRACE, and CHAMP RO data with those of ionosondes. The absolute errors of our results are much smaller than these results, indicating an extremely good agreement between CSES and COSMIC RO NmF2 and further confirming that CSES RO are also within the general error limit as proposed by Habarulema et al. (2014).

The better result of daytime data in this study is in accordance with the conclusion obtained by Wu et al. (2009) and Yue et al. (2011). As we know, the nighttime data have a more complex spatial distribution pattern compared to daytime data, because daytime data are affected by solar radiation, which makes the global distribution pattern of the ionosphere simpler during the daytime. A larger inversion error will be produced when facing an uneven spatial distribution of electron density due to the violence of the spherical symmetry assumption of the Abel inversion method. The complex nighttime spatial distribution can also be proved by the smaller correlation distance during nighttime than that of daytime, as discussed in Sect. 3.2 (Shim et al., 2008).

Besides data obtained on geomagnetically quiet days, data obtained under geomagnetic storm conditions are also quite consistent with each other, demonstrating that the RO data between CSES and COSMIC can remain consistent even under disadvantageous conditions. $\mathrm{Hu}$ et al. (2014) suggested that COSMIC measurements are acceptable under geomagnetically disturbed conditions when comparing COSMIC RO data with observations obtained from 2008 to 2013 at Sanya, a lower-latitude ionosonde in China. We therefore deduce that CSES RO data may be acceptable under geomagnetically disturbed conditions, and we will validate this when enough RO data are accumulated.

As suggested by Schreiner et al. (2007), co-located RO soundings allow the precision of the technique to be estimated, but not the accuracy. The results of the nearly-zero bias for both daytime and nighttime data and for the overall data, the normal distribution of the data difference, and the extremely high correlation coefficient between CSES $N m \mathrm{~F} 2$ and COSMIC NmF2 demonstrate that the CSES NmF2 data are highly consistent and identical with COSMIC measurements, even under geomagnetically disturbed conditions. The consistency and identical nature indicate a similar precision of the two sets. Given the reliability (accuracy) of the COSMIC data proved by many previous studies, we believe that the CSES NmF2 measurements are also quite reliable. Since the co-located data points are globally distributed, the comparison results can be generalized to the overall CSES $N m \mathrm{~F} 2$ dataset obtained so far.

\subsection{Comparison of $h m \mathrm{~F} 2$}

The height of the maximum peak values in the F2 layer, $h m \mathrm{~F} 2$, is also a very important parameter for ionospheric studies. We therefore also compare this parameter using the corresponding COSMIC dataset.

Comparison of the $h m \mathrm{~F} 2$ values between the two sets using the same method as that for $N m \mathrm{~F} 2$, the scatter plot of $h m \mathrm{~F} 2$, and the histogram of the data differences are given in Fig. 6. Data points exceeding 3 times of RMSE, shown as open circles in Fig. 6a, can be deleted from the selected datasets when calculation is implemented. Again, all the peak height points obtained under geomagnetic disturbed conditions (red points) are within the $3 \sigma$ limits, as shown in Fig. 6a. It can be seen clearly in Fig. 6a, most of the outliers (open circles) are obviously above the dashed line, which means that occasionally RO data from the CSES dataset will strongly overestimate $h m \mathrm{~F} 2$ values.

The correlation coefficient of $h m \mathrm{~F} 2$ is 0.9385 , slightly lower than that of the $N m \mathrm{~F} 2$, but can also pass the significance test of confidence level 0.01 , which also indicates a very good agreement between the two sets of $h m \mathrm{~F} 2$. The mean of the $h m \mathrm{~F} 2$ data differences (CSES $h m \mathrm{~F} 2$ minus COS$\mathrm{MIC} h m \mathrm{~F} 2$ ) is $0.59 \mathrm{~km}$, which indicates slightly higher $h m \mathrm{~F} 2$ for the CSES peak height values, and the RMSE is $12.28 \mathrm{~km}$. $h m \mathrm{~F} 2$ data difference between the two sets is so small that it can be regarded as nearly-zero bias.

Compared with $N m \mathrm{~F} 2, h m \mathrm{~F} 2$ data fluctuate more violently. It can be seen from Fig. 6a that some data points obviously deviate from the data cluster, or from the equal-value dashed line. Data points above the dashed line indicate that CSES $h m \mathrm{~F} 2 \mathrm{~s}$ are greater than the corresponding COSMIC data, while data points below the dashed line indicate that the COSMIC $h m \mathrm{~F} 2 \mathrm{~s}$ are greater than that of CSES. Larger errors are produced by these obviously deviating situations. In spite of the data fluctuation, the nearly-zero bias between the two sets, namely the mean data differences, are so small that it can be neglected, which is in accordance with the nearly normal distribution of data differences, as shown in Fig. 6b. The high correlation coefficient and the normally distributed data differences again indicate that the overall $h m \mathrm{~F} 2$ data of the two sets are in good agreement.

We also compare the daytime and nighttime $h m \mathrm{~F} 2 \mathrm{~s}$, and the corresponding scatter plots are given in Fig. 7. The correlation coefficient for daytime data is 0.9671 and that for nighttime 0.8510 . Similar to $N m \mathrm{~F} 2$, daytime $h m \mathrm{~F} 2$ has a better correlation coefficient.

The mean data difference for daytime $h m \mathrm{~F} 2 \mathrm{~s}$ is $0.40 \mathrm{~km}$ with a RMSE of $8.59 \mathrm{~km}$, while the mean data difference for nighttime $h m \mathrm{~F} 2 \mathrm{~s}$ is $0.62 \mathrm{~km}$ with a RMSE of $14.30 \mathrm{~km}$. The positive means of data differences for both daytime and nighttime data indicate that the overall CSES $h m F 2 s$ are slightly greater than that of the COSMIC, but they are so small that they can be neglected. The greater RMSE of the nighttime data indicates an obviously more fluctuating nighttime $h m \mathrm{~F} 2$ compared to the daytime $h m \mathrm{~F} 2$.

The bias and RMSE for overall, daytime, and nighttime data are given in Table 2 for a comparison. 

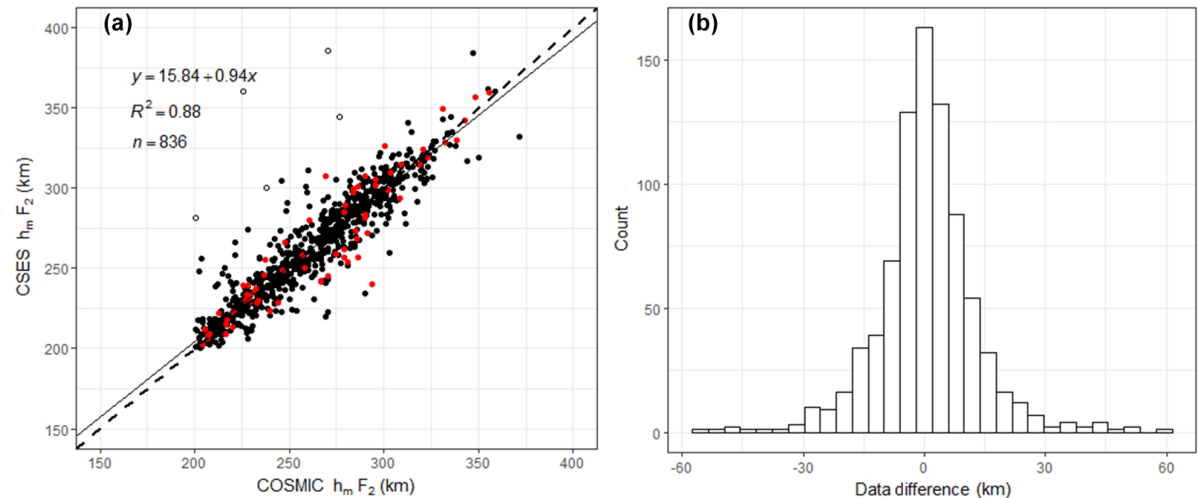

Figure 6. Scatter plot of $h m \mathrm{~F} 2 \mathrm{~s}$ for CSES and COSMIC and histogram of their differences. The dashed line is the equal-value line with a slope of 1 , and the solid line is the linear fitting line. The $y$ axis refers to the CSES $h m \mathrm{~F} 2$, and the $x$ axis to COSMIC $h m \mathrm{~F} 2$. Open circles are points exceeding 3 times the standard deviation of data differences between matched points. Red points are peak height obtained under geomagnetic conditions of Dst $<-30 \mathrm{nT}$.
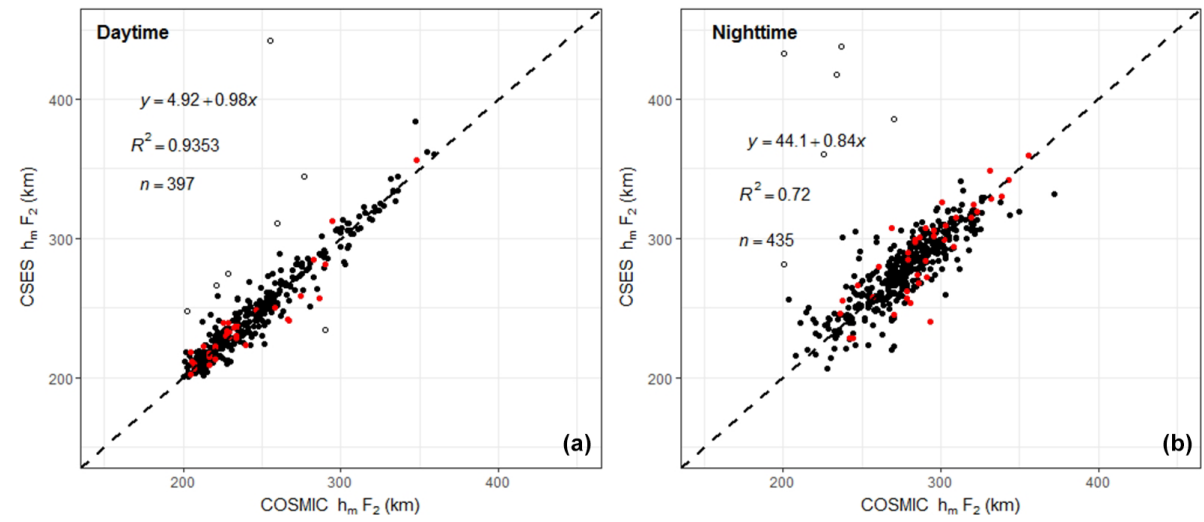

Figure 7. Scatter plot of $h m \mathrm{~F} 2$ for daytime and nighttime data. The dashed line in Fig. 5 is the equal-value line with a slope of 1.

Table 2. Absolute error of $h m \mathrm{~F} 2$ between CSES and COSMIC.

\begin{tabular}{lrrr}
\hline & $\begin{array}{r}\text { Correlation } \\
\text { coefficient }\end{array}$ & Mean $(\mathrm{km})$ & RMSE $(\mathrm{km})$ \\
\hline Total & 0.9385 & 0.59 & 12.28 \\
Daytime & 0.9671 & 0.40 & 8.59 \\
Nighttime & 0.8510 & 0.62 & 14.30 \\
\hline
\end{tabular}

From the results shown in Tables 2 and 1, it can be seen that the correlation of $N m \mathrm{~F} 2$ is better than that of $h m \mathrm{~F} 2$ between the two sets. This result is in accordance with the conclusion that the RO measurements were better in $N m \mathrm{~F} 2$ than in $h m F 2$ (Chuo et al., 2011). Another point is that the daytime $h m \mathrm{~F} 2 \mathrm{~s}$ are in better agreement than the nighttime data, which are similar to $N m \mathrm{~F} 2$ data.

The overall comparison results of $h m \mathrm{~F} 2$ are very good when compared to prior COSMIC RO data validation results using ionosonde observations. Chuo et al. (2013) reported an $h m \mathrm{~F} 2$ agreement of about 0.87 using observations in the low-latitude Southern Hemisphere from May 2006 to April 2008. Krankowski et al. (2011) got a correlation coefficient of 0.949 when comparing COSMIC $h m F 2$ data observed in 2008 with those from ionosondes in European midlatitudes. The high correlation coefficients of our result indicate that the two sets are in good agreement, and the high correlation coefficients between COSMIC $h m \mathrm{~F} 2$ and ionosondes from previous studies can further prove that CSES $h m \mathrm{~F} 2 \mathrm{~s}$ are consistent with ionosonde observations based on the correlation transitive rule mentioned in Sect. 3.1.

Krankowski et al. (2011) obtained a bias of $2.8 \mathrm{~km}$ and a standard deviation of $11.5 \mathrm{~km}$ when validating the COSMIC $h m F 2$ data. Cherniak and Zakharenkova (2014) showed that COSMIC $h m F 2 s$ were in a good agreement with Kharkov ISR observations of different seasons in 2008-2009, and bias and standard deviations are less than 24 and $29 \mathrm{~km}$ respectively. Habarulema et al. (2014) obtained an error limit of about $30 \mathrm{~km}$ when comparing COSMIC hmF2s with midlatitude ionosondes using data in 2008. Yue et al. (2011) suggested that the retrieval uncertainty in $h m \mathrm{~F} 2$ is about $10 \mathrm{~km}$ for the COSMIC simulation analysis. The nearly-zero bias 
and the small RMSE between $h m \mathrm{~F} 2$ of CSES and COSMIC demonstrate that the $\mathrm{F}$ region peak height parameters obtained by CSES and COSMIC are extremely similar, or in another way, $h m \mathrm{~F} 2 \mathrm{~s}$ from the two sets have similar precision and accuracy. We therefore deduce that error between CSES $h m \mathrm{~F} 2$ and ground-based $h m \mathrm{~F} 2$ is comparable to prior results according to error propagation rules.

As a result, the significant correlation coefficient and very small absolute RMSE in this study indicate the consistent variations and similar precision of $h m \mathrm{~F} 2$ between CSES and COSMIC, and the nearly-zero bias indicates the two sets have similar accuracy. All of these results indicate that CSES RO-retrieved $h m \mathrm{~F} 2 \mathrm{~s}$ are reliable considering the reliability of COSMIC RO data validated by many previous studies.

\subsection{Comparison of electron density profiles (EDPs)}

Besides the two most important parameters $N m \mathrm{~F} 2$ and $h m \mathrm{~F} 2$, EDPs are also very important because EDPs can provide electron densities at different altitudes to depict ionospheric 3-D images from the bottom of the ionosphere to the altitude of the LEO satellite.

As EDPs from CSES and COSMIC have different altitudes due to the different satellite altitudes of the two missions, only data under the altitude of the CSES satellite can be compared from the co-located profiles. We therefore compare the retrieved EDP data at some selected altitudes as the numbers of data points are not identical for each matched profile pair, and altitudes of retrieved data are not identical for the two co-located profile pairs either.

For each altitude specified in Sect. 2.3, we calculate the average data between $\pm 10 \mathrm{~km}$ altitude of each profile and then calculate the correlation coefficients using all the average data pairs at that altitude. The results of all selected altitudes are given in Table 3. Figure 8 gives the scatter plots of all these altitudes, and data obtained under geomagnetically disturbed conditions are shown in red points; also shown in the figure are the linear fitting equations, goodness-of-fit coefficients, and numbers of data points involved in the calculation. Outliers are eliminated from the datasets using the same criteria mentioned above.

All the correlation coefficients in Table 3 can pass the significance test of confidence level 0.01 , which means that data points at different altitudes are highly correlated. When combining all the results together, we can deduce that the co-located profiles from CSES and COSMIC sets are quite similar to each other in spite of the global distribution of these profile pairs, as shown in Fig. 2 in Sect. 2.2. According to some studies, COSMIC profiles are in very good agreement with observations from different ISRs (Lei et al., 2007; Kelley et al., 2009; Cherniak and Zakharenkova, 2014). Pedatella et al. (2015) compared COSMIC RO data at different altitudes with in situ observations from CHAMP and C/NOSF missions and obtained correlation coefficients higher than 0.90 , proving the consistency of the COSMIC profiles with in situ satellite observations. Based on the high consistency between CSES and COSMIC profile pairs and previous COSMIC EDP validation results, we can deduce that CSES profiles may generally agree with ISR profiles according to similarity transitive rules mentioned earlier (Langford et al., 2001), which we will further prove by using ISR observations in our subsequent work.

Schreiner et al. (2007) showed that RMS is about $10^{3} \mathrm{~cm}^{-3}$ between 150 and $500 \mathrm{~km}$ altitude, whereas below $150 \mathrm{~km}$ the RMS increases to a maximum of about $3 \times 10^{3} \mathrm{~cm}^{-3}$ at about $100 \mathrm{~km}$, when comparing the RO profiles from different COSMIC satellites within $5 \mathrm{~km}$ distance. Comparing COSMIC profiles with ISR observations, Lei et al. (2007) suggested inversed errors are larger than $10^{5} \mathrm{~cm}^{-3}$ at altitudes below $\sim 150 \mathrm{~km}$, and Cherniak and Zakharenkova (2014) obtained an error range of $12-16 \times$ $10^{4} \mathrm{~cm}^{-3}$. Pedatella et al. (2015) obtained an overall bias of $0.22 \times 10^{5} \mathrm{~cm}^{-3}$ with a standard deviation of $0.65 \times$ $10^{5} \mathrm{~cm}^{-3}$, and relative bias and standard deviation are $14.9 \%$ and $10.4 \%$ respectively, when validating COSMIC data at different altitudes using CHAMP in situ observations; they also compared COSMIC data with the in situ observations from the C/NOFS mission and got a relative bias of $5.6 \%$ with a standard deviation $12.4 \%$. They attributed the better agreement with in situ observations from C/NOFS to the higher altitude of this satellite. Both the absolute and relative errors, as well as error variation with altitude, shown in Table 3 , are in accordance with those studies, suggesting that the CSES EDPs are reliable and within general error limits due to the high similarity and consistency between CSES and COSMIC EDPs.

From the correlation coefficients given in Table 3, it can be seen that correlation coefficients above $200 \mathrm{~km}$ are obviously higher than those below this altitude. The absolute mean differences at different altitudes are comparable to each other. However, relative differences at different altitudes are quite different; relative mean differences above $200 \mathrm{~km}$ are extremely small, while relative mean differences below this altitude (including this altitude) increase dramatically. We obtained from Fig. 5 that the peak heights $h m \mathrm{~F} 2$ of most profiles are located between 200 and $350 \mathrm{~km}$; the obviously high correlation coefficients in these regions indicate that RO-retrieved data at and above peak height are more consistent with each other, whereas discrepancies between the two datasets below the peak regions are much larger. This can be explained by the distribution characteristics of the different ionospheric layers, and by the spherical assumption used in the Abel inversion method. As we know, electron density fluctuations in regions above the F2 peak become smaller under geomagnetically quiet conditions if compared with that at lower altitudes due to the relatively lower density according to electron density attenuation rules; it is therefore easier to satisfy the spherical symmetry assumption when using the Abel inversion method in this region. This spherical symmetry assumption is by far the most significant error source 
Table 3. Correlation coefficients and RMSEs for the data at different altitudes of the profiles.

\begin{tabular}{llrr|rr}
\hline $\begin{array}{l}\text { Altitude } \\
(\mathrm{km})\end{array}$ & $\begin{array}{l}\text { Correlation } \\
\text { coefficient }\end{array}$ & \multicolumn{2}{c|}{ Absolute error } & \multicolumn{2}{c}{ Relative error } \\
\cline { 3 - 6 } & & $\begin{array}{r}\text { Mean data } \\
\text { difference }\end{array}$ & RMSE & $\begin{array}{r}\text { Mean relative data } \\
\text { differences }\end{array}$ & $\begin{array}{r}\text { Relative } \\
\text { RMSE }\end{array}$ \\
\hline 500 & 0.9749 & $-0.01982 \times 10^{5}$ & $0.8824 \times 10^{5}$ & $-1.72 \%$ & $35.90 \%$ \\
450 & 0.9882 & $-0.01551 \times 10^{5}$ & $0.1070 \times 10^{5}$ & $-0.69 \%$ & $27.30 \%$ \\
400 & 0.9929 & $-0.01923 \times 10^{5}$ & $0.1314 \times 10^{5}$ & $-0.59 \%$ & $20.29 \%$ \\
350 & 0.9927 & $-0.02274 \times 10^{5}$ & $0.1946 \times 10^{5}$ & $0.74 \%$ & $23.45 \%$ \\
300 & 0.9908 & $-0.01881 \times 10^{5}$ & $0.2700 \times 10^{5}$ & $1.89 \%$ & $25.16 \%$ \\
250 & 0.9874 & $-0.03198 \times 10^{5}$ & $0.3309 \times 10^{5}$ & $4.70 \%$ & $61.29 \%$ \\
200 & 0.9691 & $-0.01090 \times 10^{5}$ & $0.3909 \times 10^{5}$ & $25.83 \%$ & $133.77 \%$ \\
150 & 0.9564 & $-0.03161 \times 10^{5}$ & $0.2958 \times 10^{5}$ & $43.28 \%$ & $324.74 \%$ \\
100 & 0.8883 & $-0.02330 \times 10^{5}$ & $0.2611 \times 10^{5}$ & $78.40 \%$ & $518.99 \%$ \\
\hline
\end{tabular}
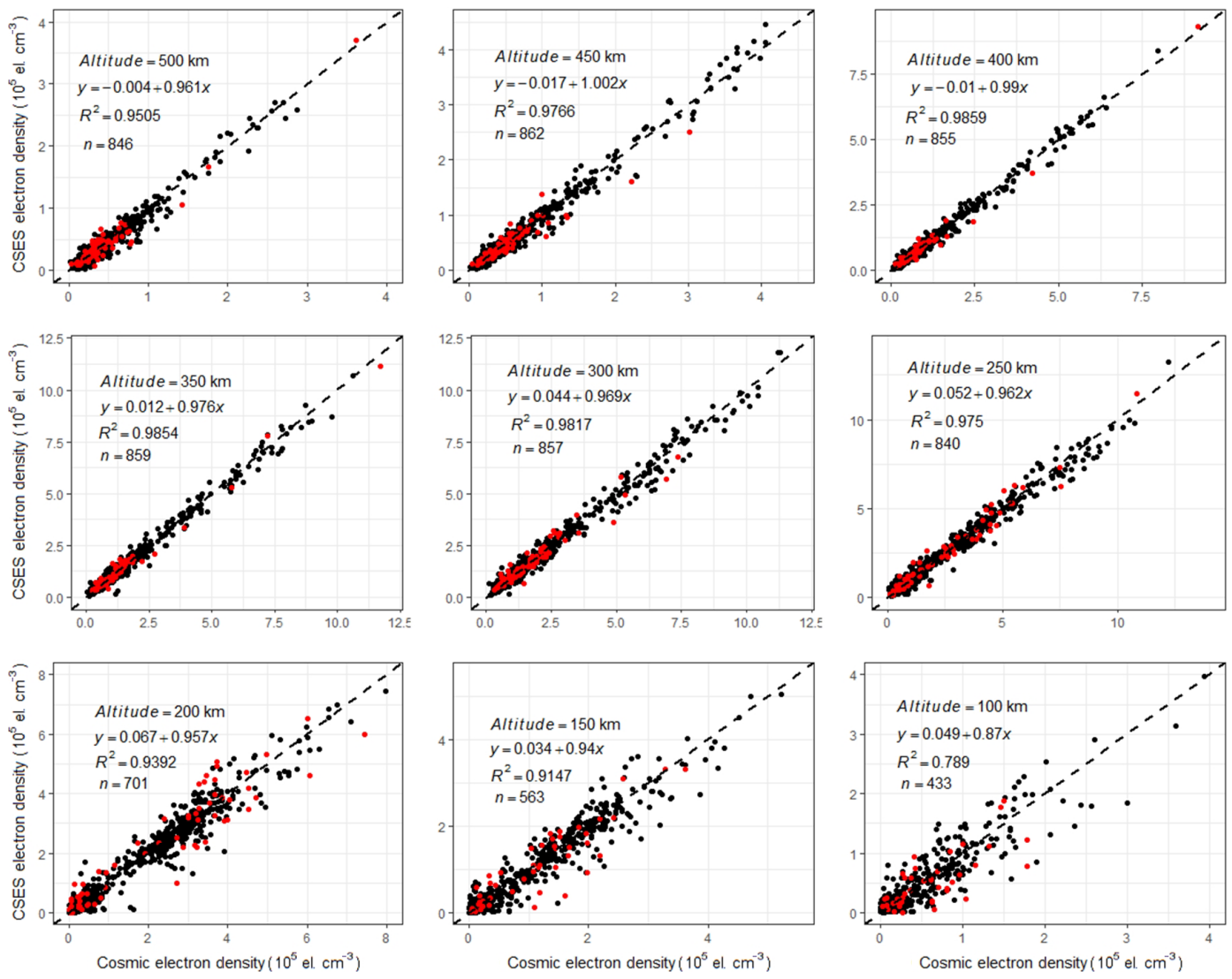

Figure 8. Scatter plots of data from matched profiles at different altitudes. The dashed line in Fig. 5 is the equal-value line with a slope of 1.

in the retrieval of the electron density profiles (Lei et al., 2007). In addition, a shorter propagating distance in the topside ionosphere for the radio signals from GPS to LEO will lead to a smaller error of straight line propagation assumption. As suggested by Liu et al. (2010), COSMIC RO can obtain reasonably correct electron densities around and above the F2 peak; however, the assumption of spherical symmetry introduces artificial plasma cave and plasma tunnel structures as well as electron density enhancement at the geomagnetic equator at and below $250 \mathrm{~km}$ altitude, which will enlarge data discrepancies, as shown in Table 3. Syndergaard et al. (2006) also suggested larger errors at the bottom of the retrieved profiles. The results shown in Table 3 in this study are in accordance with those studies, demonstrating that CSES EDPs have larger errors for data below $200 \mathrm{~km}$ altitude, which is similar to that of COSMIC. 
An obvious characteristic shown in Table 3 is that all the means of data difference are negative values, though they are very small compared to the original measurements, which means the overall CSES data at different altitudes are lower than the corresponding COSMIC data. The all negative mean data differences at different altitudes may indicate a possible systematic bias between the two measurements. These systematically lower values at all altitudes is most likely caused by the first-order estimation of the electron density at the altitude of the CSES satellite, rather than the spatial differences of the co-located profile pairs, because spatial differences lead to random errors. However, further confirmation of this error source is required. It is also necessary to point out that the signs of the mean relative data differences at altitudes $\geq 400 \mathrm{~km}$ are negative, similar to the signs of the corresponding absolute errors, whereas the signs of the mean relative data differences at altitudes below $400 \mathrm{~km}$ are positive, just on the contrary to the signs of absolute mean data differences. Further analysis shows that the opposite signs are caused by points where CSES data are much higher than COSMIC data and thus lead to much larger relative errors, which further indicates that data below the peak regions, especially below about $150 \mathrm{~km}$, fluctuate more violently.

Besides spherical symmetry and straight line propagation assumptions, the larger discrepancies at altitudes below peak regions can be explained by the different spatial locations of the matched profiles. Although the peak values of co-located profile pairs are near each other according to selection criteria, data points other than peak values on the matched profile pairs may exceed the selection criteria and result in larger distances due to the different tangent point path of the matched profile pairs. As a result, a larger distance will lead to larger discrepancies between the corresponding datasets. In addition, the tangent point path of the matched profiles may have different directions, which will lead to different inversion results because the retrieved data represent average electron densities along the radio ray path. In regions with large horizontal gradients, the different ray path can cause obvious differences between the matched profiles. At altitudes below $200 \mathrm{~km}$, especially below $150 \mathrm{~km}$, sporadic E layers can cause large horizontal gradients and then lead to large inversion errors. Wu et al. (2009) suggested that the large relative error below $150 \mathrm{~km}$ is due to the errors transferred from upper altitudes (the F layer) and the very small electron density at that altitude. They also suggested that the larger ray separations can induce larger errors which can be transferred to low altitudes; phase measurement errors induce small relative fluctuations in the electron density in the topside ionosphere but can cause large relative fluctuations in the low-altitude ionosphere, because small electron density at low altitude is sensitive to the phase errors. It is therefore concluded that many sources can cause large errors for measurements at altitudes below $150 \mathrm{~km}$, which as a result lead to the large discrepancies between CSES and COSMIC RO data at the bottom of the ionosphere.
Based on the above analysis, we conclude that CSES RO profiles are generally very consistent with those of COSMIC and are reliable for data applications due to the wide acceptance and application of COSMIC RO data. However, larger discrepancies are found at lower altitudes between the two sets compared to data differences at higher altitudes. Therefore, special attention should be paid to data below $200 \mathrm{~km}$ in future applications due to the relatively large discrepancies between the two datasets.

\section{Summary and conclusions}

Validation of the CSES RO data was carried out to estimate the consistency and reliability of the CSES RO data using the globally distributed measurements from the COSMIC mission covering the date range from 12 February 2018 to 31 March 2019, as the consistency and reliability of COSMIC RO data have been widely validated using data from different measurements on a global scale. Comparing CSES $N m \mathrm{~F} 2, h m \mathrm{~F} 2$, and EDP data at some selected altitudes, with corresponding COSMIC RO data, we obtain the following results.

CSES $N m$ F2 data are highly consistent with that from COSMIC, with a correlation coefficient of 0.9898 . The mean data difference is $0.005363 \times 10^{5} \mathrm{~cm}^{-3}$ with a RMSE of $0.3638 \times 10^{5} \mathrm{~cm}^{-3}$; the relative mean difference is $1.97 \%$ with a relative RMSE of $16.17 \%$. Correlation between daytime $N m \mathrm{~F} 2$ data is obviously better than that of nighttime $N m \mathrm{~F} 2$ data.

CSES $h m \mathrm{~F} 2$ data are also very consistent with COSMIC data, with a correlation coefficient of 0.9385 . The bias between the two sets is $0.59 \mathrm{~km}$ with a RMSE of $12.28 \mathrm{~km}$. Again, daytime $h m \mathrm{~F} 2$ has a better correlation than nighttime data.

Co-located profiles between CSES and COSMIC are generally very consistent with each other, with a better agreement for data at peak height regions $(200 \mathrm{~km})$ and above than for those below these regions. For EDP data below $200 \mathrm{~km}$ altitude, special attention should be paid due to the relatively larger discrepancies between the two sets.

Based on the validation results between COSMIC data and different measurements obtained by many previous studies and the validation results between COSMIC and CSES RO data obtained in this study, it is deduced that CSES RO data are within the error limits obtained by previous studies according to error propagation rules.

The GOX payload on board CSES satellite can obtain over 500 occultation events each day, which provide a large dataset for the study of the 3-D distribution of the ionospheric electron density when combined with the in situ electron density measurements obtained by the LAP on board CSES. The relatively thorough comparison work in this paper demonstrates that the CSES RO data are very consistent with the corresponding COSMIC data, proving that the CSES RO 
data are reliable for applications on ionosphere-related problems considering the wide applications of the COSMIC RO data. However, many RO related studies suggest that the asymmetry of the electron density distribution is the main source of the Abel inversion transformation (Schreiner et al., 1999; Syndergaard et al., 2006; Lei et al., 2007), and this inversion error varies with solar activity, season, geomagnetic latitude, and local time (Wu et al., 2009). The CSES RO data in this study cover all the latitudes and four seasons with fixed local times under lower solar activity conditions, and solar activity in this study is similar to that in most of the COSMIC validation studies; the comparison results will therefore applicable to data with similar low solar activity conditions. More subsequent validation work will be conducted and presented using data accumulated under different solar activities.

Data availability. The COSMIC Radio Occultation data used in this paper can be downloaded from https://cdaac-www.cosmic.ucar. edu/ (last access: 22 August 2019), and the CSES Radio Occultation data can be downloaded from http://www.leos.ac.cn (last access: 27 September 2019).

Author contributions. XW arranged this study, including experiment design and data analysis. WC and ZZ collected the COSMIC data used in this paper. SX, DY, and JC did some calculation work to search co-located data.

Competing interests. The authors declare that they have no conflict of interest.

Special issue statement. This article is part of the special issue "Satellite observations for space weather and geo-hazard". It is not associated with a conference.

Acknowledgements. COSMIC Radio Occultation data can be downloaded from https://cdaac-www.cosmic.ucar.edu/ (last access: 22 August 2019). CSES Radio Occultation data can be downloaded from http://www.leos.ac.cn (last access: 27 September 2019).

Financial support. This research has been supported by the National Key R\&D Program of China (grant no. 2018YFC1503505), and by the Foundation of Institute of Crustal Dynamics, CEA (grant nos. ZDJ2018-18 and ZDJ2019-03).

Review statement. This paper was edited by Livio Conti and reviewed by two anonymous referees.

\section{References}

Anthes, R. A., Bernhardt, P. A., Chen, Y., Cucurull, L., Dymond, K. F., Ector, D., Healy, S. B., Ho, S.-P., Hunt, D. C., Kuo, Y.-H., Liu, H., Manning, K., McCormick, C., Meehan, T. K., Randel, W. J., Rocken, C., Schreiner, W. S., Sokolovskiy, S. V., Syndergaard, S., Thompson, D. C., Trenberth, K. E., Wee, T.-K., Yen, N. L., and Zeng, Z.: The COSMIC/FORMOSAT-3 Mission: Early Results, B. Am. Meteorol. Soc., 89, 313-334, https://doi.org/10.1175/bams-89-3-313, 2008.

Beyerle, G.: GPS radio occultation with GRACE: Atmospheric profiling utilizing the zero difference technique, Geophys. Res. Lett., 32, L13806, https://doi.org/10.1029/2005g1023109, 2005.

Cheng Y., Lin J., Shen X. H., Wan X., Li X. X., and Wang W. J.: Analysis of GNSS radio occultation data from satellite ZH-01, Earth Planet. Phys., 2, 499-504, https://doi.org/10.26464/epp2018048, 2018.

Cherniak, I. V. and Zakharenkova, I. E.: Validation of FORMOSAT3/COSMIC radio occultation electron density profiles by incoherent scatter radar data, Adv. Space Res., 53, 1304-1312, https://doi.org/10.1016/j.asr.2014.02.010, 2014.

Chu, Y.-H., Su, C.-L., and Ko, H.-T.: A global survey of COSMIC ionospheric peak electron density and its height: A comparison with ground-based ionosonde measurements, Adv. Space Res., 46, 431-439, https://doi.org/10.1016/j.asr.2009.10.014, 2010.

Chuo, Y.-J., Lee, C.-C., Chen, W.-S., and Reinisch, B. W.: Comparison between bottomside ionospheric profile parameters retrieved from FORMOSAT3 measurements and ground-based observations collected at Jicamarca, J. Atmos. Sol.-Terr. Phys., 73, 1665-1673, https://doi.org/10.1016/j.jastp.2011.02.021, 2011.

Chuo, Y. J., Lee, C. C., Chen, W. S., and Reinisch, B. W.: Comparison of the characteristics of ionospheric parameters obtained from FORMOSAT-3 and digisonde over Ascension Island, Ann. Geophys., 31, 787-794, https://doi.org/10.5194/angeo-31-7872013, 2013.

Habarulema, J. B., Katamzi, Z. T., and Yizengaw, E.: A simultaneous study of ionospheric parameters derived from FORMOSAT-3/COSMIC, GRACE, and CHAMP missions over middle, low, and equatorial latitudes: Comparison with ionosonde data, J. Geophys. Res.-Space, 119, 7732-7744, https://doi.org/10.1002/2014ja020192, 2014.

Hajj, G. A. and Romans, L. J.: Ionospheric electron density profiles obtained with the Global Positioning System: Results from the GPS/MET experiment, Radio Sci., 33, 175-190, https://doi.org/10.1029/97rs03183, 1998.

Hu, L., Ning, B., Liu, L., Zhao, B., Chen, Y., and Li, G.: Comparison between ionospheric peak parameters retrieved from COSMIC measurement and ionosonde observation over Sanya, Adv. Space Res., 54, 929-938, https://doi.org/10.1016/j.asr.2014.05.012, 2014.

Jakowski, N., Wehrenpfennig, A., Heise, S., Reigber, C., Lühr, H., Grunwaldt, L., and Meehan, T. K.: GPS radio occultation measurements of the ionosphere from CHAMP: Early results, Geophys. Res. Lett., 29, 95-1-954, https://doi.org/10.1029/2001g1014364, 2002.

Kelley, M. C., Wong, V. K., Aponte, N., Coker, C., Mannucci, A. J., and Komjathy, A.: Comparison of COSMIC occultationbased electron density profiles and TIP observations with Arecibo incoherent scatter radar data, Radio Sci., 44, RS4011, https://doi.org/10.1029/2008rs004087, 2009. 
Krankowski, A., Zakharenkova, I., Krypiak-Gregorczyk, A., Shagimuratov, I. I., and Wielgosz, P.: Ionospheric electron density observed by FORMOSAT-3/COSMIC over the European region and validated by ionosonde data, J. Geodesy, 85, 949-964, https://doi.org/10.1007/s00190-011-0481-z, 2011.

Kuo, Y.-H., Wee, T.-K., Sokolovskiy, S., Rocken, C., Schreiner, W., Hunt, D., and Anthes, R.: Inversion and Error Estimation of GPS Radio Occultation Data, J. Meteorol. Soc. Jpn., 82, 507-531, https://doi.org/10.2151/jmsj.2004.507, 2004.

Lai, P.-C., Burke, W. J., and Gentile, L. C.: Topside electron density profiles observed at low latitudes by COSMIC and compared with in situ ion densities measured by C/NOFS, J. Geophys. Res.-Space, 118, 2670-2680, https://doi.org/10.1002/jgra.50287, 2013.

Langford, E., Schwertman, N., and Owens, M.: Is the Property of Being Positively Correlated Transitive?, Am. Stat., 55, 322-325, https://doi.org/10.1198/000313001753272286, 2001.

Lei, J., Syndergaard, S., Burns, A. G., Solomon, S. C., Wang, W., Zeng, Z., Roble, R. G., Wu, Q., Kuo, Y.-H., Holt, J. M., Zhang, S.-R., Hysell, D. L., Rodrigues, F. S., and Lin, C. H.: Comparison of COSMIC ionospheric measurements with ground-based observations and model predictions: Preliminary results, J. Geophys. Res.-Space, 112, A07308, https://doi.org/10.1029/2006ja012240, 2007.

Liu, J. Y., Lin, C. Y., Lin, C. H., Tsai, H. F., Solomon, S. C., Sun, Y. Y., Lee, I. T., Schreiner, W. S., and Kuo, Y.-H.: Artificial plasma cave in the low-latitude ionosphere results from the radio occultation inversion of the FORMOSAT-3/COSMIC, J. Geophys. Res.Space, 115, A07319, https://doi.org/10.1029/2009ja015079, 2010.

Lomidze, L., Knudsen, D. J., Burchill, J., Kouznetsov, A., and Buchert, S. C.: Calibration and Validation of Swarm Plasma Densities and Electron Temperatures Using Ground-Based Radars and Satellite Radio Occultation Measurements, Radio Sci., 53, 15-36, https://doi.org/10.1002/2017rs006415, 2018.

McNamara, L. F. and Thompson, D. C.: Validation of COSMIC values of foF2 and M(3000)F2 using groundbased ionosondes, Adv. Space Res., 55, 163-169, https://doi.org/10.1016/j.asr.2014.07.015, 2015.

Pedatella, N. M., Yue, X., and Schreiner, W. S.: Comparison between GPS radio occultation electron densities and in situ satellite observations, Radio Sci., 50, 518-525, https://doi.org/10.1002/2015rs005677, 2015.

Rocken, C., Kuo, Y.-H., Schreiner, W., Hunt, D., Sokolovskiy, S., and McCormick, C.: COSMIC system description, Terr. Atmos. Ocean Sci., 11, 21-52, https://doi.org/10.3319/TAO.2000.11.1.21(COSMIC), 2000.

Schreiner, W., Rocken, C., Sokolovskiy, S., Syndergaard, S., and Hunt, D.: Estimates of the precision of GPS radio occultations from the COSMIC/FORMOSAT-3 mission, Geophys. Res. Lett., 34, L04808, https://doi.org/10.1029/2006g1027557, 2007.

Schreiner, W. S., Sokolovskiy, S. V., Rocken, C., and Hunt, D. C.: Analysis and validation of GPS/MET radio occultation data in the ionosphere, Radio Sci., 34, 949-966, https://doi.org/10.1029/1999rs900034, 1999.

Shen, X., Zhang, X., Yuan, S., Wang, L., Cao, J., Huang, J., Zhu, X., Piergiorgio, P., and Dai, J.: The state-ofthe-art of the China Seismo-Electromagnetic Satellite mis- sion, Science China Technological Sciences, 61, 634-642, https://doi.org/10.1007/s11431-018-9242-0, 2018.

Shim, J. S., Scherliess, L., Schunk, R. W., and Thompson, D. C.: Spatial correlations of day-to-day ionospheric total electron content variability obtained from ground-based GPS, J. Geophys. Res.-Space, 113, A09309, https://doi.org/10.1029/2007ja012635, 2008.

Syndergaard, S., Schreiner, W. S., Rocken, C., Hunt, D. C., and Dymond, K. F.: Preparing for COSMIC: Inversion and analysis of ionospheric data products, in Atmosphere and Climate: Studies by Occultation Methods, edited by: Foelsche, U., Kirchengast, G., and Steiner, A. K., 137-146, Springer, New York, 2006.

Thampi, S. V., Yamamoto, M., Lin, C., and Liu, H.: Comparison of FORMOSAT-3/COSMIC radio occultation measurements with radio tomography, Radio Sci., 46, RS3001, https://doi.org/10.1029/2010rs004431, 2011.

Wang, X., Cheng, W., Yang, D., and Liu, D.: Preliminary validation of in situ electron density measurements onboard CSES using observations from Swarm Satellites, Adv. Space Res., 64, 982994, https://doi.org/10.1016/j.asr.2019.05.025, 2019.

Wickert, J., Michalak, G., Schmidt, T., Beyerle, G., Cheng, C.-Z., and Healy, S. B.: GPS Radio Occultation: Results from CHAMP, GRACE and FORMOSAT-3/COSMIC, Terr. Atmos. Ocean. Sci., 20, 35-50, https://doi.org/10.3319/tao.2007.12.26.01(f3c), 2009.

Wu, X., Hu, X., Gong, X., Zhang, X., and Wang, X.: Analysis of inversion errors of ionospheric radio occultation, GPS Solut., 13, 231-239, https://doi.org/10.1007/s10291-008-0116-x, 2009.

Wu, K.-H., Su, C.-L., and Chu, Y.-H.: Improvement of GPS radio occultation retrieval error of $\mathrm{E}$ region electron density: COSMIC measurement and IRI model simulation, J. Geophys. Res.-Space, 120, 2299-2315, https://doi.org/10.1002/2014ja020622, 2015.

Yang, K.-F., Chu, Y.-H., Su, C.-L., Ko, H.-T., and Wang, C.-Y.: An Examination of FORMOSAT-3/COSMIC Ionospheric Electron Density Profile: Data Quality Criteria and Comparisons with the IRI Model, Terr. Atmos. Ocean. Sci., 20, 193-206, https://doi.org/10.3319/tao.2007.10.05.01(f3c), 2009.

Yue, X., Wan, W., Liu, L., and Mao, T.: Statistical analysis on spatial correlation of ionospheric day-to-day variability by using GPS and Incoherent Scatter Radar observations, Ann. Geophys., 25, 1815-1825, https://doi.org/10.5194/angeo-25-1815-2007, 2007.

Yue, X., Schreiner, W. S., Rocken, C., and Kuo, Y.-H.: Evaluation of the orbit altitude electron density estimation and its effect on the Abel inversion from radio occultation measurements, Radio Sci., 46, RS1013, https://doi.org/10.1029/2010rs004514, 2011.

Yue, X., Schreiner, W. S., Kuo, Y.-H., Wu, Q., Deng, Y., and Wang, W.: GNSS radio occultation (RO) derived electron density quality in high latitude and polar region: NCAR-TIEGCM simulation and real data evaluation, J. Atmos. Sol.-Terr. Phy., 98, 39-49, https://doi.org/10.1016/j.jastp.2013.03.009, 2013. 